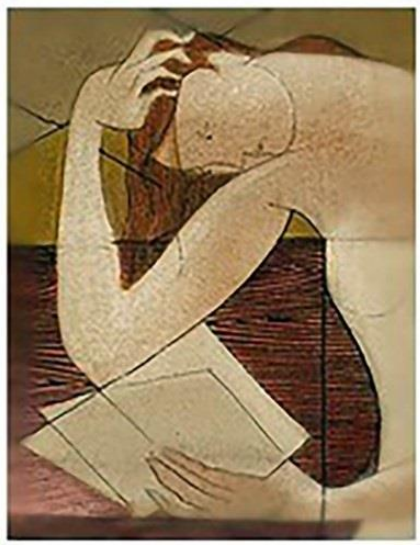

Nau Literária

crítica e teoria da literatura em língua portuguesa

PPG-LET UFRGS

ISSN 1981-4526

https://seer.ufrgs.br/NauLiteraria

V. 17, n.1 - 2021

Dossiê Clarice Lispector: Iluminações para o tempo presente

\title{
Memórias do centenário de Clarice Lispector nos acervos digitais Memories of Clarice Lispector's centenary in digital collections
}

Débora Regina Bacega ${ }^{1}$

Resumo: Este artigo discorre sobre as práticas transversais da memória que circularam nas redes digitais durante a comemoração do centenário da escritora Clarice Lispector no ano de 2020. Nota-se que essas práticas acionam tanto acervos pessoais quanto editoriais da autora nas teias comunicacionais. Nesse ínterim, o fazer-memória se faz pela reapresentação das narrativas compreendidas nesses acervos. Assim, busca-se problematizar como essas práticas corroboram com a rememoração da autora e sua obra também na ambiência digital. Para tanto, aciona-se reflexões de estudiosos dos aspectos comunicacionais, arquivísticos e socioculturais da memória. Neste estudo de caso, adota-se como corpus os lançamentos comemorativos do site.claricelispector.ims.com.br, do Podcast da Clarice, da hashtag \#365diasdeClarice nas redes sociais Facebook e Instagram e das edições especiais dos livros da escritora. Espera-se demonstrar como essas práticas comunicacionais e da memória podem contribuir para a renovação periódica do acervo literário e cultural de Clarice Lispector também no tempo presente.

Palavras-chave: memória, acervo digital; literatura; centenário; Clarice Lispector.

Abstract: In the meantime, memory-making is done by re-presenting the narratives included in these collections. Thus, the purpose is to comprehend how these practices corroborate the remembrance of the author and her work also in the digital environment. For this, reflections from scholars of the communicational, archival and sociocultural aspects of memory are triggered. In this case study, commemorative inaugurations of site.claricelispector.ims.com.br, Clarice Podcast, hashtag \# 365diasdeClarice on the social networks Facebook and Instagram and special editions of the writer's books are adopted as corpus. It is expected to demonstrate how these communication and memory practices can contribute to the periodic renewal of Clarice Lispector's literary and cultural collection also in the present time.

Keywords: memory; digital collection; literature; centenary; Clarice Lispector.

\section{Considerações iniciais}

O centenário de nascimento da escritora Clarice Lispector passa a ser amplamente comemorado nas redes digitais por meio de iniciativas comunicacionais, editoriais e arquivísticas durante o ano de 2020. Entendemos que neste ato de rememorar convoca-se não apenas a sua escrita, mas também testemunhos, fotografias, pinturas, cartas, objetos que se mostram como rastros mnésicos e suportam a lembrança, ainda que em reminiscências, das

\footnotetext{
${ }^{1}$ Doutoranda e mestre em Comunicação e Práticas de Consumo pelo PPGCOM ESPM/SP. Bolsista CAPES PROSUP. Integrante do Mnemon (Grupo de Pesquisa em Memória, comunicação e consumo), certificado CNPq/ ESPM. deborabacega@gmail.com.
} 


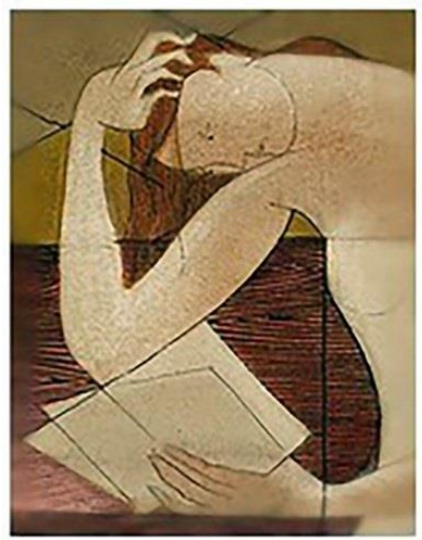

Nau Literária

crítica e teoria da literatura em língua portuguesa

PPG-LET UFRGS

ISSN 1981-4526

https://seer.ufrgs.br/NauLiteraria

V. 17, n.1 - 2021

Dossiê Clarice Lispector: Iluminações para o tempo presente

múltiplas facetas de Clarice Lispector: mulher, mãe, esposa, irmã, pintora, cronista, contista, romancista. Assim, a vontade de lembrar reflete a faceta afetual que traduz sua literatura em experiência literária e, como tal, extrapola os estudos formativos sobre a autora.

Nesse sentido, percebemos que os acervos pessoais e literários da escritora se tornam objetos de práticas memorialísticas. Essas práticas, por sua vez, articulam o fazer-memória por meio da reapresentação das narrativas biográficas e editoriais de Clarice Lispector também na ambiência midiática, ainda que reconheçamos as suas incompletudes. Dessa forma, pretendemos discorrer sobre as práticas transversais da memória motivadas pela comemoração do centenário do nascimento da escritora. Assim, buscamos responder à seguinte questão: como essas práticas corroboram para a rememoração dos acervos da autora e de sua obra também na ambiência digital, principalmente, num momento em que a pandemia de Covid-19 impôs isolamento social, dificultando dinâmicas presenciais ou visitação de espaços públicos? Ainda que o momento pandêmico não seja o objeto de nossa discussão, faz-se necessário salientar a sua relevância nesta análise.

Nosso percurso se atenta às dimensões midiática, arquivística e cultural da literatura da escritora e suas interfaces com as práticas comunicacionais e mnemônicas. Para tanto, trazemos este estudo de caso que se concentra na observação de quatro lançamentos comemorativos do centenário da escritora: 1) o site.claricelispector.ims.com.br; 2) o Podcast da Clarice; 3) a hashtag \#365diasdeClarice nas redes sociais Facebook e Instagram e 4) a reimpressão de suas obras em edições especiais. Neste trabalho, tentamos analisar cada uma dessas iniciativas a partir das reflexões de estudiosos dos aspectos arquivísticos e socioculturais da memória. Nessa toada, buscamos demonstrar como essas práticas transversais da memória podem contribuir para a renovação periódica do acervo literário e cultural de Clarice Lispector cem anos depois. 


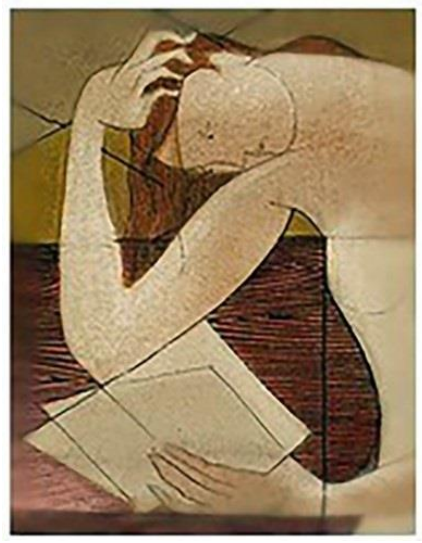

Nau Literária

crítica e teoria da literatura em língua portuguesa

PPG-LET UFRGS

ISSN 1981-4526

https://seer.ufrgs.br/NauLiteraria

V. 17, n.1 - 2021

Dossiê Clarice Lispector: Iluminações para o tempo presente

\section{Manuscritos, cadernos e pinturas: memórias nas teias digitais}

A memória, enquanto operação coletiva dos acontecimentos e das interpretações do passado, pode definir ou reforçar sentimentos de pertencimento e fronteiras entre grupos sociais distintos: partidos, sindicatos, famílias, nações etc. Em certa medida, a referência ao passado promete a coesão dos grupos e das instituições que compõem uma sociedade, ou seja, a memória é enquadrada nos relatos oficiais, nas vozes autorizadas, nos objetos materiais como monumentos, museus, bibliotecas etc. Porém, este trabalho de enquadramento de memória se satura porque existem vozes dissidentes que também podem atuar tanto individualmente quanto coletivamente na sociedade. Assim, Pollak (1989, p. 203) amplia a discussão sobre a memória quando nos sinaliza que esta: "é seletiva. nem tudo fica gravado. nem tudo fica registrado". O sociólogo ressalta que as datas e os acontecimentos são estruturados do ponto de vista político, tornando a memória enquadrada, organizada sem revelar os conflitos que, porventura, existam em relação aos indivíduos que discordam das versões oficiais. Na visão do sociólogo, as memórias dos dissidentes são subterrâneas em relação aos discursos hegemônicos. Consequentemente, a memória se torna objeto de disputas. (POLLAK, 1989).

Por sua vez, Jô Gondar (2005, p. 16) destaca que as dimensões políticas e éticas estão implicadas na memória social uma vez que esta reflete a maneira como refletimos sobre o passado em prol do futuro que desejamos. Assim, nossas escolhas sobre o que conservar e o que questionar são sempre intencionais quanto ao porvir, o que nos torna responsáveis ética e politicamente. Nesse ínterim, a pesquisadora propõe situarmos a memória enquanto reconstrução processual e não mera representação do passado uma vez que esta também se refere aos sentidos, gestos, práticas, ações políticas e aos afetos. Dessa forma, a memória pode ser compreendida como "uma tentativa de dar sentido e direção" ao que nos afetou. (GONDAR, 2005, p. 25).

Já o historiador Paul Ricoeur (2007, p. 156) fundamenta que o testemunho dá à memória seu caráter declarativo, ou seja, por meio da linguagem narra-se um acontecimento de "forma 


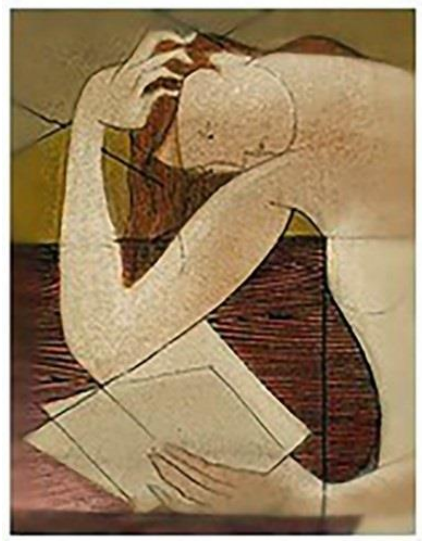

Nau Literária

crítica e teoria da literatura em língua portuguesa

PPG-LET UFRGS

ISSN 1981-4526

https://seer.ufrgs.br/NauLiteraria

V. 17, n.1 - 2021

Dossiê Clarice Lispector: Iluminações para o tempo presente

bastante expressiva: “Eu estava lá””. Assim, por meio da oralidade, essa memória declarativa ainda conta com a potência viva do corpo (a voz, os gestos, as entonações). Desse modo, sugere o autor, o testemunho pode apoiar ou complementar os outros suportes físicos mnésicos, sendo muitas vezes, utilizado como fonte de proposições jurídicas ou históricas. No entanto, como Ricoeur alerta, o testemunho caracteriza-se também por fragilidades, incoerências, imperfeições, e, não menos, por simulações. Nesse sentido, confiar na palavra de outrem pressupõe, em certa medida, manter a prudência como regra e, se necessário, recorrer à dúvida. Isso se faz necessário, afirma Ricoeur, porque a memória também pode ser manipulada em seus usos e abusos de forma que algumas testemunhas passam a ser consideradas essenciais ou históricas enquanto outras jamais tiveram audiência para seus relatos.

Por outro lado, o Ricoeur sinaliza que, do ponto epistemológico da memória, a transcrição do testemunho, ou seja, a passagem da narração para a escrita traduziria a memória declarada em arquivo e, consequentemente, em prova documental. Ricoeur define arquivo como lugar físico e social que abriga o destino deste rastro documental. Nas palavras do pensador francês, trata-se da passagem da memória declarada para a memória arquivada. No entanto, a constituição deste arquivo está subordinada ao recorte narrativo uma vez que algo pode ser, simplesmente, deixado de lado e não fazer parte de um determinado arquivo. Assim, o estudioso da memória reitera que a condição de prova documental não isenta este arquivo de questionamentos em relação à sua intenção veritativa (RICOEUR, 2007).

Ainda em relação à incompletude dos arquivos, o sociólogo Fausto Colombo (1991) ressalta que o valor da lógica arquivística na contemporaneidade concentra-se no fato de que a conservação se faz necessária. Sob essa perspectiva, o autor reitera que a lembrança de um determinado objeto é que o torna valioso e não o seu contrário. Para o professor italiano, há uma "obsessão social que detesta o esquecimento e remove o esquecido como uma inquietante prova da impossibilidade de um arquivamento totalizante" (COLOMBO, 1991, p. 103). Na visão do pesquisador, o ato de recordar ou praticar a memória deixa de ser relevante quando se 


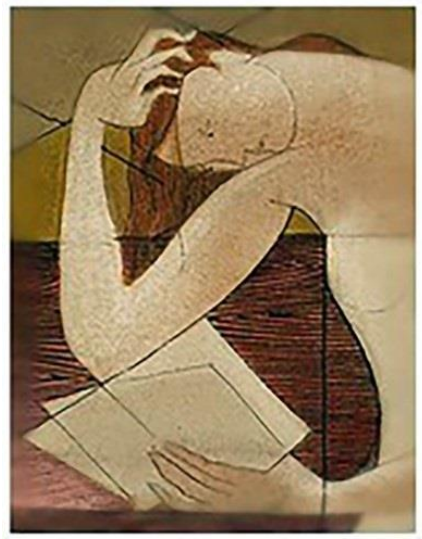

Nau Literária

crítica e teoria da literatura em língua portuguesa

PPG-LET UFRGS

ISSN 1981-4526

https://seer.ufrgs.br/NauLiteraria

V. 17, n.1 - 2021

Dossiê Clarice Lispector: Iluminações para o tempo presente

pensamos que a recordação está ali depositada em algum sistema arquivístico e sua recuperação, em certo sentido, se torna possível a qualquer tempo. Em relação à potência do esquecimento, Colombo explica que determinadas atitudes culturais podem interagir com uma série de descobertas técnicas e científicas que preservem a construção das memórias, por exemplo, em sua versão eletrônica com a função específica de reduzir ou anular qualquer possibilidade de esquecimento. No entanto, aponta o autor, torna-se necessário admitir que tanto o esquecimento quanto a limitação dessas práticas arquivísticas são factíveis quando pensamos nas formas de armazenamento e na permanência ou manutenção destes sistemas de memória (COLOMBO, 1991).

A partir desses aportes teóricos, iniciamos nossa análise com a apresentação do site dedicado à escritora, lançado em 2020 por conta das comemorações do centenário, disponível em site.claricelispector.ims.com.br. Nele, o usuário pode navegar por cinco seções intituladas Vida, Livro a Livro, Uma aprendizagem, Acervo e Postagens, como ilustra a figura 1. Cada um desses tópicos apresenta informações, imagens, vídeos e conteúdos noticiosos ou literários sobre a escritora. Apesar deste espaço virtual ser recente, o acervo de Clarice Lispector faz parte do Instituto Moreira Salles (IMS) desde 2004. Como informado pela entidade, o site.claricelispector.ims.com.br disponibiliza integralmente a reprodução na ambiência digital de manuscritos, datiloscritos, correspondências, cadernos e quadros pintados pela escritora ${ }^{2}$.

\footnotetext{
${ }^{2}$ Disponível em https://site.claricelispector.ims.com.br/acervo/ Acesso em: mar.2021
} 

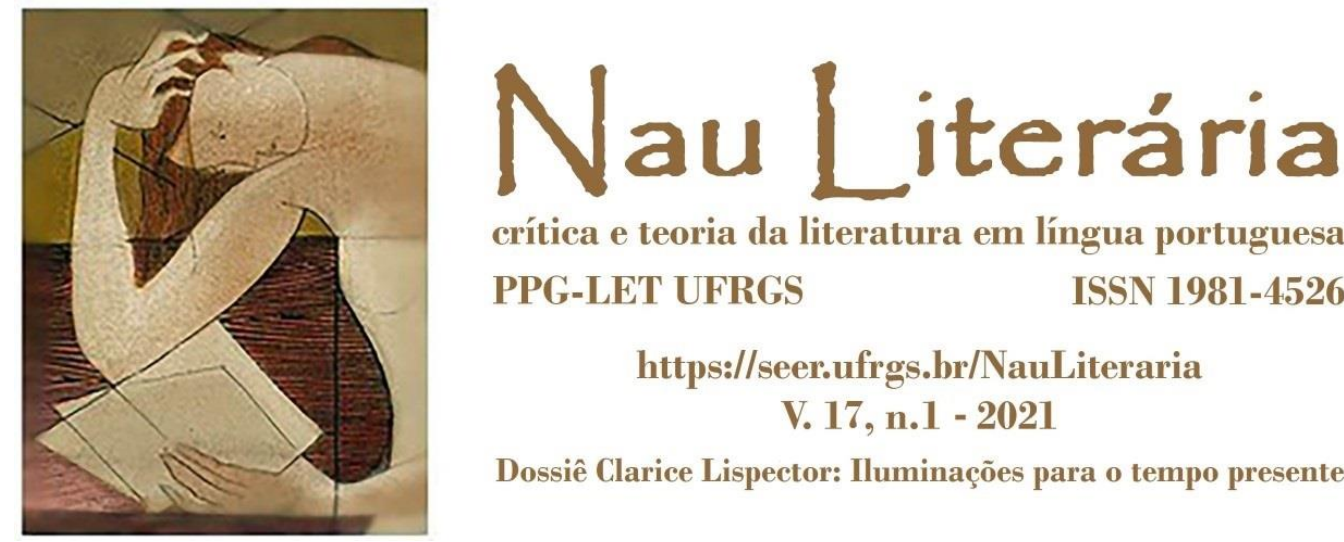

crítica e teoria da literatura em língua portuguesa PPG-LET UFRGS

ISSN 1981-4526

https://seer.ufrgs.br/NauLiteraria

V. 17, n.1 - 2021

Dossiê Clarice Lispector: Iluminações para o tempo presente

Figura 1 - Tela capturada do site Clarice Lispector lançado pelo IMS em 2020

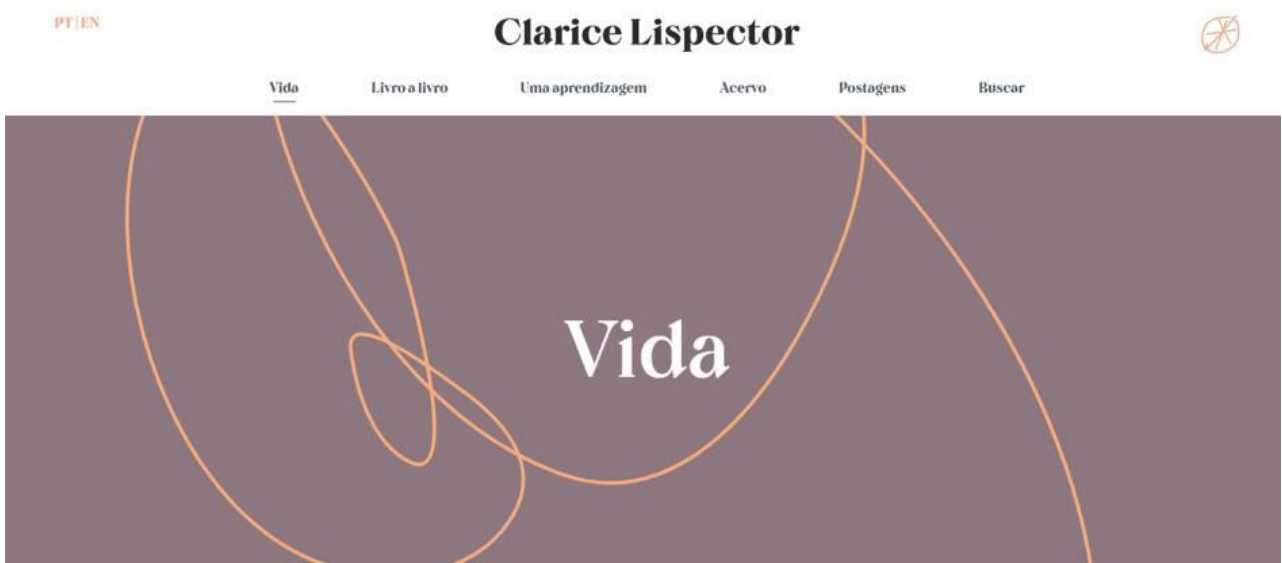

Fonte: https://site.claricelispector.ims.com.br

Observamos que a seção Livro a livro apresenta as obras de Clarice Lispector acompanhadas de um texto introdutório, talvez, para conduzir a experiência do leitor pela cronologia do acervo bibliográfico da autora como indica a figura 2.

Figura 2 - Tela capturada da seção Livro a livro do site Clarice Lispector/ IMS

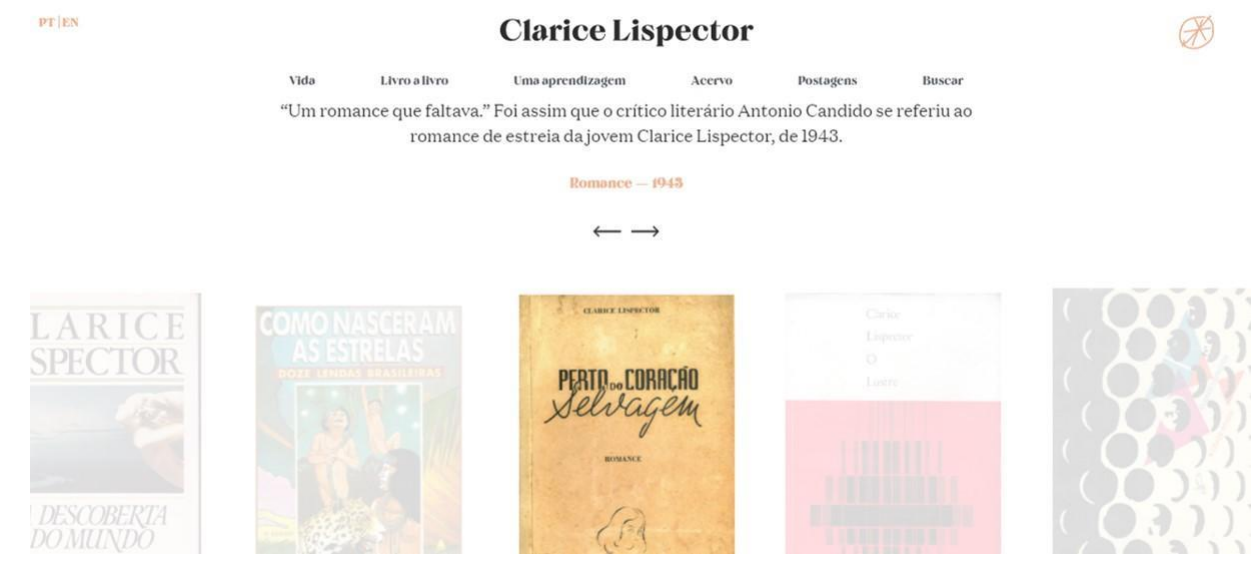

Fonte: https://site.claricelispector.ims.com.br 


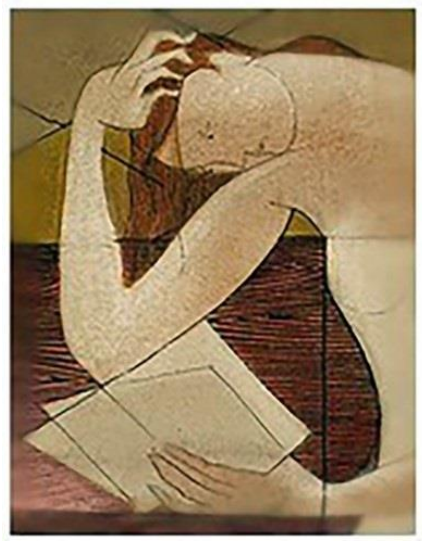

Nau Literária

crítica e teoria da literatura em língua portuguesa

PPG-LET UFRGS

ISSN 1981-4526

https://seer.ufrgs.br/NauLiteraria

V. 17, n.1 - 2021

Dossiê Clarice Lispector: Iluminações para o tempo presente

Já no item Acervo, encontramos os cadernos de anotações, desenhos e pinturas da escritora como podemos observar nas figuras 3 e 4, respectivamente. Os manuscritos, por sua vez, são transcritos na tela do site para que o usuário possa fazer a leitura dos originais.

Figura 3 - Telas capturadas da seção Acervo, da esquerda para direita, capa e primeira página do caderno The question is

\section{Caderno "The question is" Caderno "The question is"}

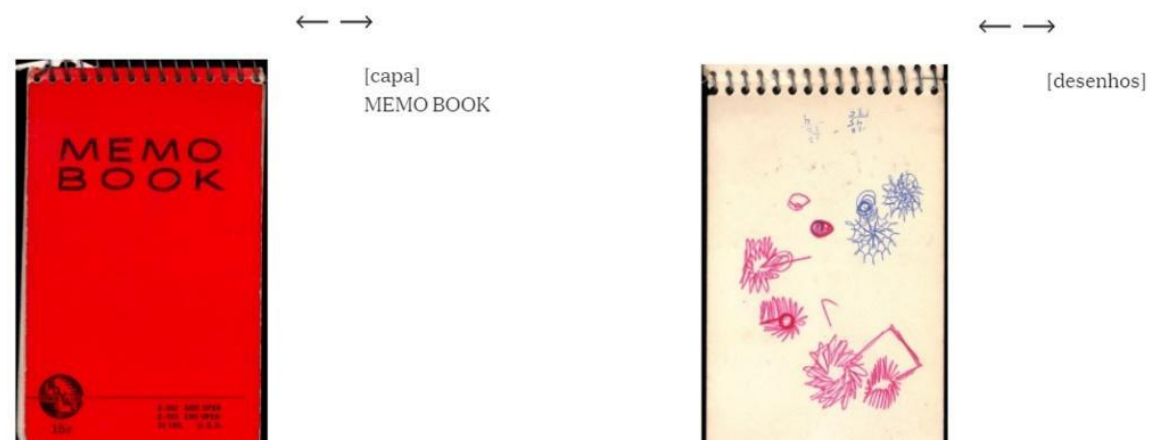

Fonte: https://site.claricelispector.ims.com.br

Em Uma aprendizagem, concentram-se os documentos produzidos sobre Clarice Lispector. Pelo sistema de buscas, disponível no site, podemos consultar artigos, ensaios, aulas, livros ou teses e dissertações que se insiram na temática clariciana. Por outro lado, textos noticiosos ou de blogs, notícias, ensaios ou editoriais sobre obra da escritora estão em Postagens. 


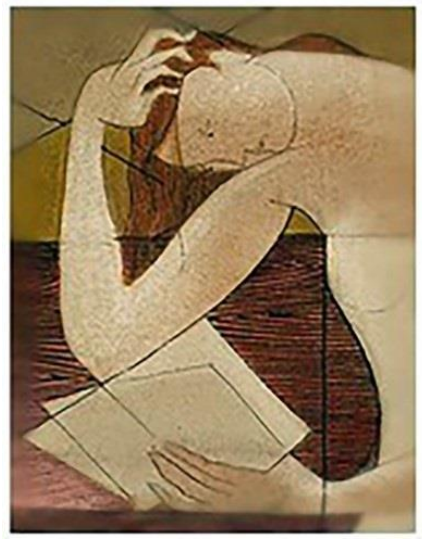

Nau Literária

crítica e teoria da literatura em língua portuguesa

PPG-LET UFRGS

ISSN 1981-4526

https://seer.ufrgs.br/NauLiteraria

V. 17, n.1 - 2021

Dossiê Clarice Lispector: Iluminações para o tempo presente

Figura 4 - Tela capturada da seção Acervo

\section{Pinturas}

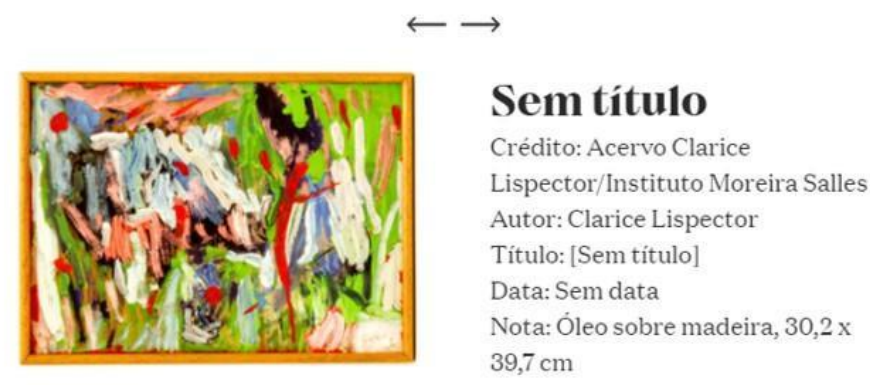

Fonte: https://site.claricelispector.ims.com.br/acervo/

Há uma página dedicada aos créditos e agradecimentos em relação ao desenvolvimento do projeto, assim como as referências e fontes das imagens e vídeos. Nesse sentido, notamos que os acervos são múltiplos, entre eles: Acervo Paulo Gurgel Valente; Arquivo Geral da Cidade do Rio de Janeiro / Coleção Augusto Malta; Fundação Casa de Rui Barbosa/ArquivoMuseu de Literatura Brasileira / Arquivo Clarice Lispector; além dos acervos do Instituto Moreira Salles (IMS), entre eles: Acervo Clarice Lispector, Acervo Elisa Lispector, Acervo Marcel Gautherot e Acervo Maureen Bisilliat ${ }^{3}$.

Entendemos essas práticas mnemônicas como recortes compreendidas em rizomas nas teias digitais uma vez que como aponta Pollak (1989) nem tudo é registrado na composição de uma memória comum em relação à escritora e seus documentos. Apesar de reunir parte de sua biografia e objetos pessoais, cabe sempre os atos de seleção, edição e escolhas no que diz respeito à tessitura mnemônica enquanto fenômeno sociocultural. Nesses enquadramentos,

\footnotetext{
${ }^{3}$ Disponível em https://site.claricelispector.ims.com.br/creditos/ Acesso em mar. 2021
} 


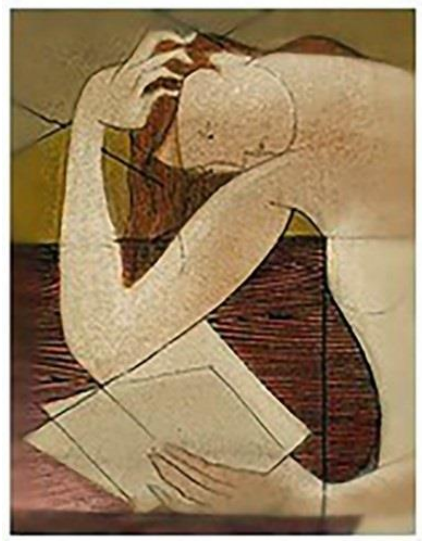

Nau Literária

crítica e teoria da literatura em língua portuguesa

PPG-LET UFRGS

ISSN 1981-4526

https://seer.ufrgs.br/NauLiteraria

V. 17, n.1 - 2021

Dossiê Clarice Lispector: Iluminações para o tempo presente

acontecimentos relevantes da vida e obra da escritora podem ter sido esquecidos como nos lembra Ricoeur (2007). Ainda sob essa ótica, atentamos para a limitação técnica do armazenamento e digitalização dos documentos, derivando, assim, a incompletude e a imperfeição deste acervo quando acionamos as reflexões do sociólogo Colombo (1991) sobre a obsessão social da memória arquivada. Apesar de reconhecermos os esforços mnésicos para o lançamento de site.claricelispector.ims.com.br, podemos deduzir que não se trata da totalidade de documentos e, mesmo que isso ocorresse, não estão a salvo do nosso esquecimento uma vez que não existe uma memória por si mesma, mas sim um esforço laborioso pela lembrança como também nos indica Ricoeur (2007).

Por outro lado, acionando as contribuições de Gondar (2005), a memória não é um retrato estático do passado, mas um processo em reconstrução no qual a dimensão afetual tem caráter determinante, pois se insere numa série de escolhas de como queremos enxergar o futuro deste presente que vivemos. Dessa forma, neste processo de reconstrução de memórias, também é possível perceber a emergência de diferentes recortes que ampliam as possibilidades de narrativas das teias rizomáticas que se formam para além dos lugares ou fóruns previamente aceitos. Uma vez nas redes digitais, essas narrativas apresentadas se tornam também transversais e se renovam periodicamente graças aos ritos de calendário, tema que discutiremos a seguir.

\section{Livros, vozes e calendários: os ritos na ambiência comunicacional}

Os pesquisadores Douglas e Isherwood (2006, p. 113) revelam que os calendários também são fontes de significados, dando sentido à passagem do tempo, procedência às obrigações e aos ciclos da vida. Consequentemente, os calendários sistematizam determinados significados em periodicidades e celebrações. Nas palavras dos autores, o universo social demanda a marcação da temporalidade do que vivemos. Nesse sentido, os calendários se 


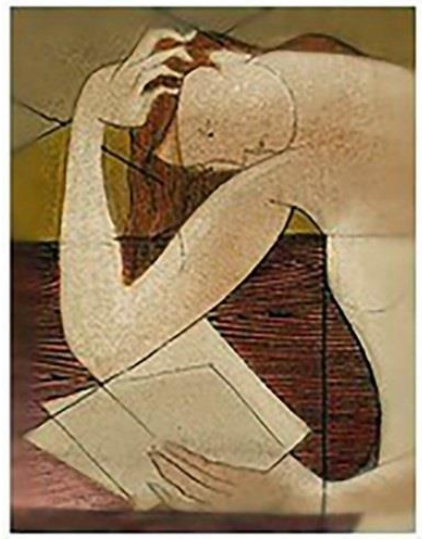

Nau Literária

crítica e teoria da literatura em língua portuguesa

PPG-LET UFRGS

ISSN 1981-4526

https://seer.ufrgs.br/NauLiteraria

V. 17, n.1 - 2021

Dossiê Clarice Lispector: Iluminações para o tempo presente

mostram em períodos anuais, semestrais, mensais, semanais e diários. Essa passagem do tempo se nutre de significados uma vez que o calendário também estabelece um início para a rotação dos deveres, para a revisão cíclica e, consequentemente, para a renovação. Os pesquisadores destacam também que essa passagem do tempo é sistematicamente contabilizada, por exemplo, vinte e cinco anos, um jubileu de prata, a celebração de centenário ou bicentenário. Em consonância com Douglas e Isherwood, estabelece-se uma relação entre o calendário e as etapas do ciclo da vida (DOUGLAS; ISHERWOOD, 2006).

Pross (1992, p. 9) afirma que a atividade social pressupõe um ritmo social ordenado pelo que ele chama de rito de calendário, conferindo equilíbrio aos ritmos cosmológico e biológico. São os ritos de calendário que orientam o rito do trabalho na sociedade, destinando parte do tempo para o lazer. O autor argumenta que os veículos de comunicação de massa, cientes desses ritos, organizam sua programação em variedades matutinas, diárias, mensais de modo a acompanhar os ritos sociais ao mesmo tempo em que buscam audiência. Nunes (1993, p. 36), em suas pesquisas sobre a paisagem radiofônica, a voz e os signos de renovação periódica e em diálogo com as reflexões de Pross (1992), elucida que a programação das rádios “distribuída pelo calendário gera atos obrigatoriamente repetidos" uma vez que se torna recorrente em determinados dias e horários para atender aos ritmos sociais e estimular a participação dos ouvintes. Por outro lado, afirma a pesquisadora, a renovação periódica dessa programação radiofônica precisa contemplar os ritos de calendário, como datas cívicas e religiosas.

Silverstone (2002, p. 156) afirma que os ritmos da vida cotidiana "dependem de nossa participação nas culturas do consumo e da mediação". Nesse sentido, argumenta o autor, a mídia adota calendários, programações e, o consumo, inclusive da mídia, se apresenta como uma atividade social. Nesse sentido, o autor elucida que "as memórias da mídia são memórias mediadas", quando a mídia decide o que rememorar - o que lembrar e o que esquecer - nas retrospectivas, o que pode acarretar, nas palavras do pesquisador, batalhas pela memória. Essas 

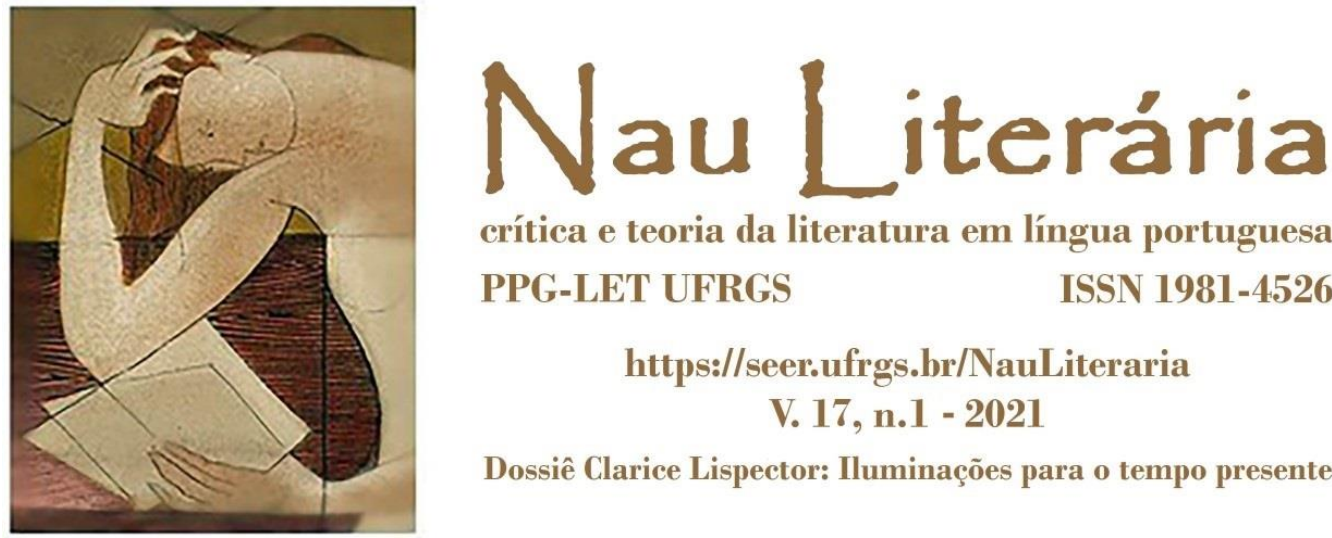

crítica e teoria da literatura em língua portuguesa

PPG-LET UFRGS

ISSN 1981-4526

https://seer.ufrgs.br/NauLiteraria

V. 17, n.1 - 2021

Dossiê Clarice Lispector: Iluminações para o tempo presente

batalhas, por sua vez, reivindicam outras interpretações do passado, reconhecendo a parcialidade da memória em comemorações, celebrações ou retrospectivas pautadas pela mídia.

Ainda pensando com Ricoeur (2007), ars memoriae ou a arte da memória se configura como uma recusa ao esquecimento. $\mathrm{O}$ estudioso da fenomenologia da memória sugere que uma memória do esquecimento para combatermos as vulnerabilidades da memória que nunca é espontânea. Em outras palavras, precisamos nos dar conta de que esquecemos algo para podermos nos lembrar de não esquecer novamente (RICOEUR, 2007).

Tendo em vista essas reflexões, seguimos em nossa discussão sobre as práticas transversais da memória. Para tanto, apresentamos o Podcast da Clarice, as hashtags \#365diasdeClarice e a reimpressão de obras em edições comemorativas cujas capas apresentam as pinturas da escritora. Comecemos com o Podcast da Clarice $^{4}$, um programa de entrevistas pautado na análise crítica das obras claricianas (vide figura 5), tendo sua primeira veiculação ainda em dezembro de 2019 e a última, 365 dias depois, em 10 de dezembro de 2020. Com quase uma hora de duração, os títulos dos 15 episódios, em ordem cronológica, são: Perto do coração selvagem e as pinturas de Clarice Lispector, O lustre - o estilo original de narrativas de Clarice Lispector, Cidade Sitiada - uma forma lírica de contar uma história, Felicidade clandestina - O inesperado a cada esquina, Bela e fera - a maturidade da jovem Clarice, Para não esquecer - Clarice Lispector mostra muitas de suas faces, Laços de Família - obra prima que nasceu aos poucos, A descoberta do mundo - crônicas que devoram a resignação, A legião estrangeira - a coragem de ser o outro que se é, Outros escritos - um mergulho na vida e nos textos de Clarice Lispector, Todas as cartas - uma bússola para a viagem pela vida de Clarice Lispector, Todas as cartas 2 - uma Bíblia clariceana, Paixão segundo GH - Em matéria de viver, nunca se pode chegar antes, Via Crucis do Corpo - 'Tudo, absolutamente tudo que Clarice escreve é revestido de erotismo', A hora da estrela - 'cada frase dela é um mundo, uma revelação'. Conduzido em sua grande maioria pelo jornalista Soares Júnior, os programas

\footnotetext{
${ }^{4}$ Disponível em https://anchor.fm/podcast-da-clarice
} 


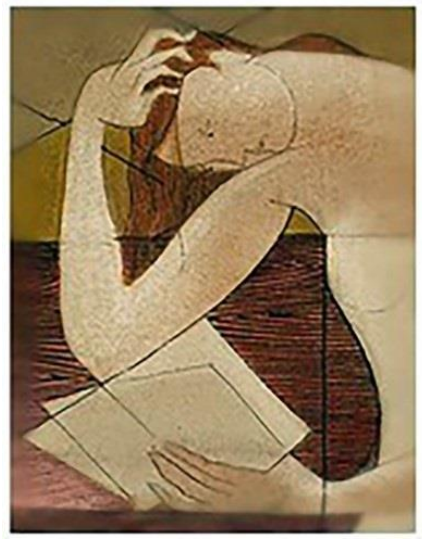

Nau Literária

crítica e teoria da literatura em língua portuguesa

PPG-LET UFRGS

ISSN 1981-4526

https://seer.ufrgs.br/NauLiteraria

V. 17, n.1 - 2021

Dossiê Clarice Lispector: Iluminações para o tempo presente

contam também com a participação da biógrafa de Clarice, Teresa Montero, e das escritoras Marina Colasanti, Nélida Piñon, Marília Librandi, da atriz Maria Fernanda Cândido, entre outras personalidades.

De acordo com as informações disponíveis no canal, esta iniciativa faz parte das ações comemorativas cujos episódios propõem apresentar detalhes e discussões sobre as obras. Neste caso, pode-se compreender o roteiro de cada episódio, a escolha dos títulos e dos convidados como uma curadoria da experiência literária que também se torna guardiã das memórias (BACEGA, 2019) de comemoração deste centenário uma vez que aciona os acervos literários da escritora em renovações periódicas de cada programa como se refere Pross (1992).

Figura 5 - Tela capturada do Podcast da Clarice

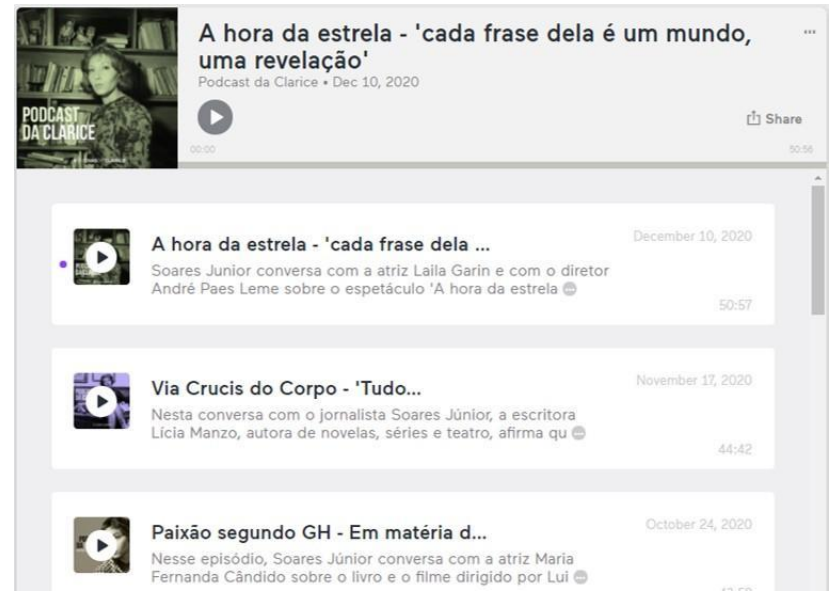

Fonte: https://anchor.fm/podcast-da-clarice

Por outro lado, entendemos que a coletânea de episódios, no formato podcast, também passa a ser um novo acervo digital sobre Clarice Lispector e, em certo sentido, um outro recorte, como mencionamos anteriormente, de sua biobibliografia baseada numa reapresentação das narrativas se traduzindo em mais uma prática transversal de seu acervo pessoal e literário. Uma 

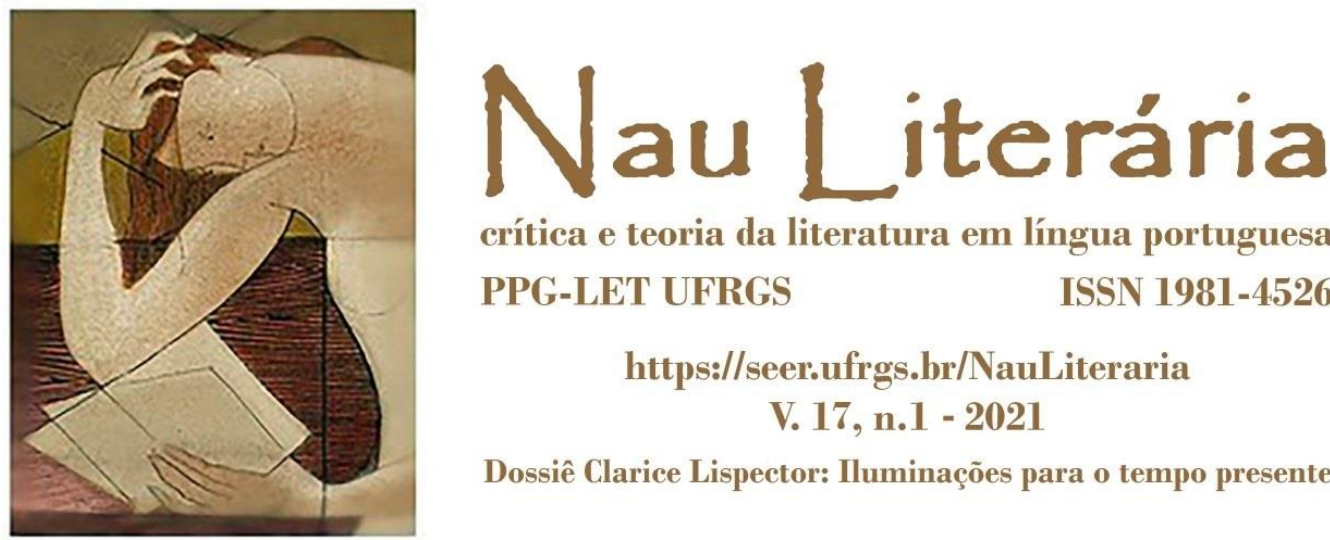

crítica e teoria da literatura em língua portuguesa

PPG-LET UFRGS

ISSN 1981-4526

https://seer.ufrgs.br/NauLiteraria

V. 17, n.1 - 2021

Dossiê Clarice Lispector: Iluminações para o tempo presente

vez nas redes, este programa pode ser ouvido a qualquer tempo, o que lhe pode conferir futuramente o caráter memorável dos conteúdos de cada um dos 15 episódios. Daí a ideia que apresentamos neste trabalho: visualizamos as memórias do centenário de Clarice Lispector também na ambiência comunicacional uma vez que como nos lembra Silverstone (2002), a mídia tem seu papel na condução de selecionar ou definir o que será ou não lembrado, por exemplo, em retrospectivas. Em nossas observações, notamos que o Podcast da Clarice tem sido uma iniciativa rememorada nas redes sociais da editora Rocco, a exemplo do que lemos na figura 6: "Maratone o Podcast da Clarice", trazendo a expressão maratonar que, atualmente, se refere ao ato de ficar assistindo a séries televisivas ou cinematográficas ininterruptamente até o último episódio.

Figura 6 - Tela capturada do Instagram da editora Rocco

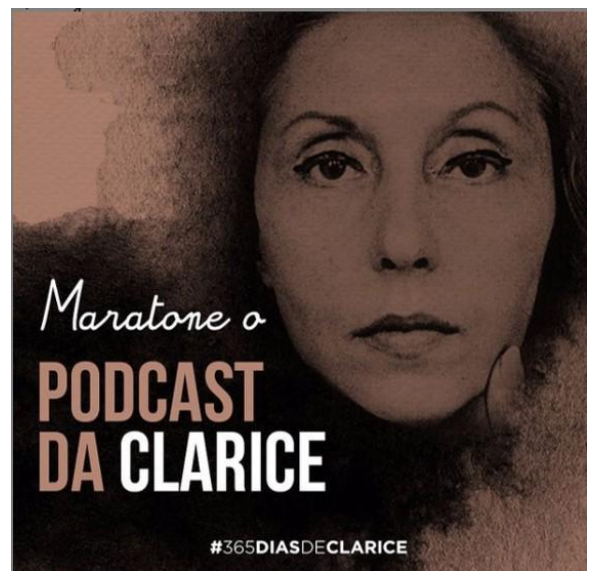

Fonte: Página do Instagram @editorarocco.

Disponível em: https://www.instagram.com/p/CJn9A6_pSva/

A exemplo do que vemos na figura 6, a hashtag \#365diasdeClarice marca as comemorações centenárias da autora, sendo utilizada nas publicações realizadas nas redes sociais Instagram e Facebook. Nesse sentido, percebemos o que Douglas e Isherwood (2006) e 


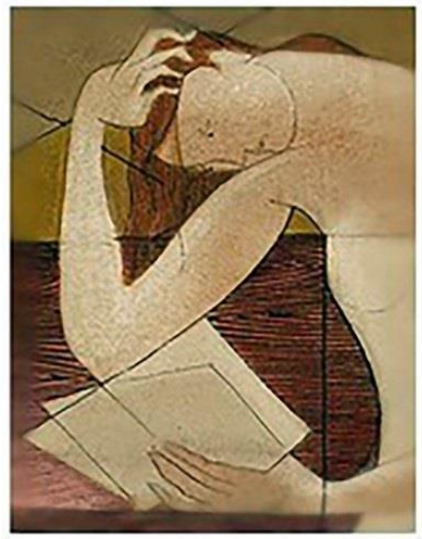

Nau Literária

crítica e teoria da literatura em língua portuguesa

PPG-LET UFRGS

ISSN 1981-4526

https://seer.ufrgs.br/NauLiteraria

V. 17, n.1 - 2021

Dossiê Clarice Lispector: Iluminações para o tempo presente

Pross (1992) abordam, respectivamente, sobre a necessidade da marcação do tempo em períodos, calendários que se traduzem em ritos. A ideia de que são 365 dias com a escritora converge para a perspectiva do que é memorável, ou seja, todos os dias durante um ano de/ com Clarice. Por outro lado, ao identificarmos a publicação da figura 6 , percebemos que, ainda em janeiro de 2021, a escritora está presente, assim como, seu podcast nas teias comunicacionais, mnemônicas e arquivísticas graças também à dinâmica das mídias.

Ainda nessa toada da marcação temporal do centenário da escritora, a editora Rocco publica frases dos livros de Clarice Lispector, acompanhada de sua imagem como ilustra a figura 7.

Figura 7 - Telas capturadas do Instagram da editora Rocco
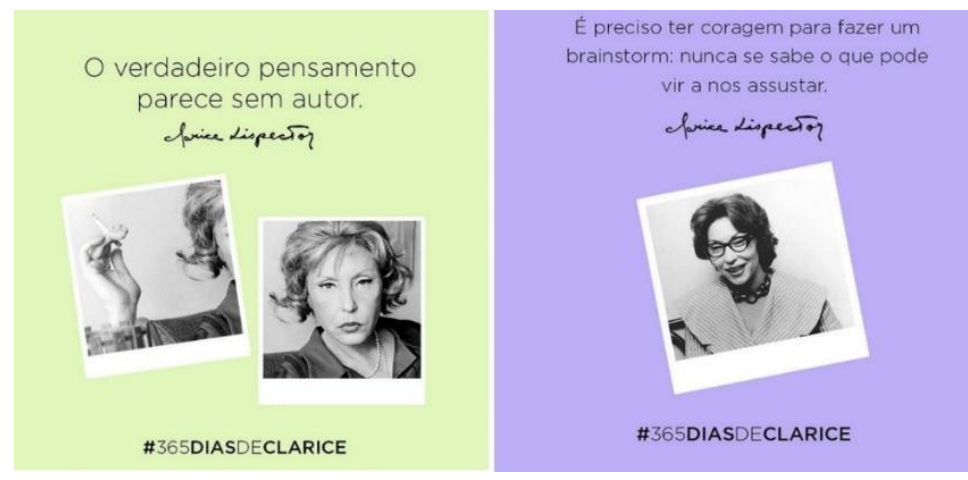

Fonte: Página do Instagram @editorarocco

Para cada uma das publicações imagéticas da série \#365diasdeClarice na página @editorarocco, há um texto no qual se explica de qual obra se refere a epígrafe em destaque. Nesse sentido, também podemos inferir a construção de um acervo literário e fotográfico da escritora baseados em sua biobibliografia. Digitalmente nomeado \#365diasdeClarice, esse recorte elucida as práticas mnemônica transversais que temos apresentado neste trabalho. 


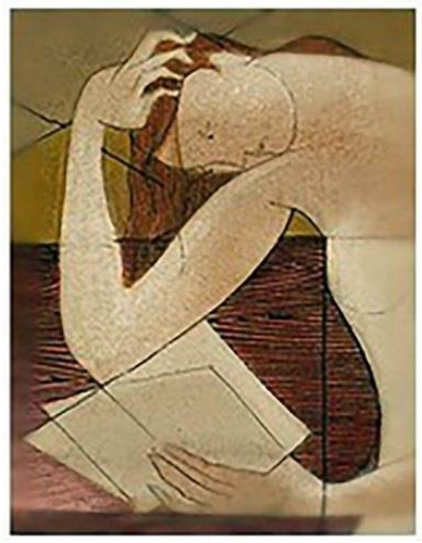

Nau Literária

crítica e teoria da literatura em língua portuguesa

PPG-LET UFRGS

ISSN 1981-4526

https://seer.ufrgs.br/NauLiteraria

V. 17, n.1 - 2021

Dossiê Clarice Lispector: Iluminações para o tempo presente

Assim como o acervo sonoro do podcast que mencionamos anteriormente, essas publicações se traduzem nas memórias dos 365 dias rumo ao centenário de Clarice. Por outro lado, como a memória não é apenas representação do passado, mas reconstrução, podemos deduzir que os trechos dos livros publicados se tornam rastros mnésicos da literatura da escritora, corroborando também para a sua renovação periódica, em diálogo com Pross, num continuum quando pensamos na tessitura do \#tbt, compressão de Throwback Thursday, uma espécie rememoração às quintas-feiras, usualmente, fomentada nas redes sociais.

Além dessas iniciativas, compreendemos que as pinturas da escritora ${ }^{5}$ passam a compor as ações comemorativas de seu centenário, uma vez que a editora Rocco faz a reimpressão do conjunto de obras claricianas em edições especiais cujas capas retratam cada uma de suas telas, como podemos notar na imagem capturada do site da editora (vide figura 8). Concomitantemente às demais, podemos inferir que o acervo biobibliográfico da escritora também passa a ser rememorado quando essas reimpressões são agrupadas em uma coletânea da celebração centenária. Consequentemente, as telas claricianas ganham a ambiência comunicacional e mnemônica.

\footnotetext{
${ }^{5}$ Ver mais em Clarice Lispector: pinturas, livro de autoria de Carlos Mendes de Sousa (2013)
} 


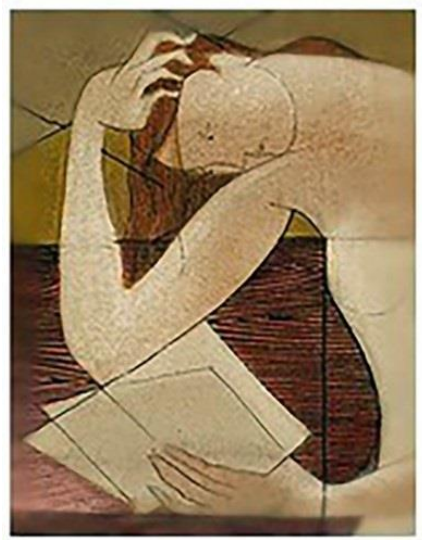

Nau Literária

crítica e teoria da literatura em língua portuguesa

PPG-LET UFRGS

ISSN 1981-4526

https://seer.ufrgs.br/NauLiteraria

V. 17, n.1 - 2021

Dossiê Clarice Lispector: Iluminações para o tempo presente

Figura 8 - Tela capturada com alguns exemplos de obras reeditadas pela Rocco

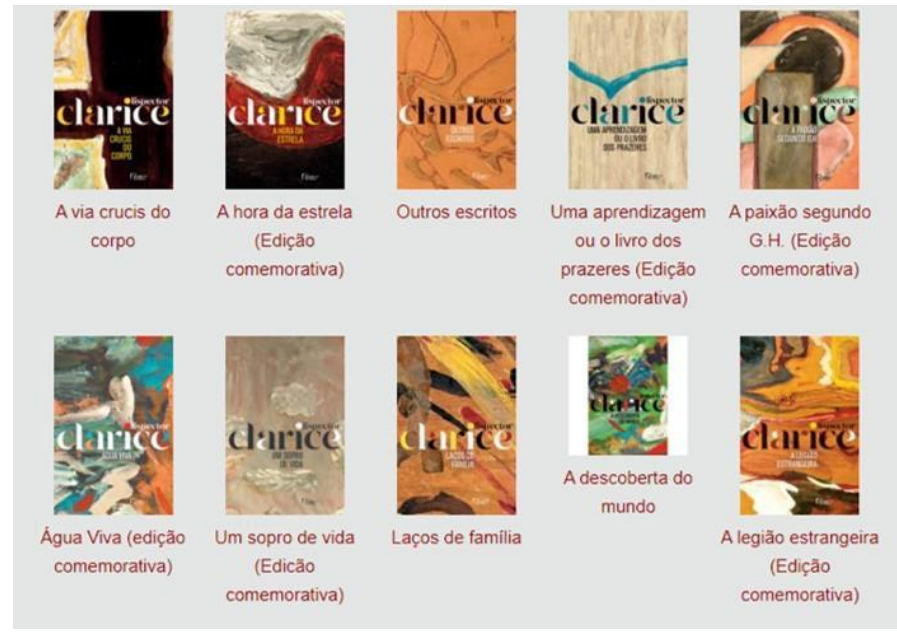

Fonte: https://www.rocco.com.br/autor/clarice-lispector/

Ainda que essas ações sejam conduzidas pela editora Rocco, compreendemos que esse grupo de práticas passa a rememorar o acervo literário sob a ótica da passagem do tempo a que se refere Douglas e Isherwood. Expliquemos: o centenário de nascimento de Clarice Lispector é um marcador social relevante para o universo sociocultural e editorial no qual se insere a literatura clariciana. Ainda que a escritora tenha falecido com quase 57 anos em 1977, podemos perceber a reconstrução processual do passado, acionando novamente Gondar (2005) de modo que a passagem do tempo se manteve contínua em ciclos memoriais projetivos e, em certa medida, utópicos. Nesse ínterim, entendemos que todo o arcabouço cultural se move com o ato de rememorar sua biobibliografia ou, em outras palavras, na busca pela lembrança de Clarice Lispector, contrapondo, assim, seu apagamento.

Nesse sentido, a memória também se torna um estratégia comunicacional e do consumo quando suas obras são relançadas passam a se inserir também nos sites de livraria ou no ecommerce da editora. Não se consome apenas a materialidade do livro em si, mas também as memórias das pinturas claricianas que, agora, se evidenciam nas capas reeditadas pela Rocco. 


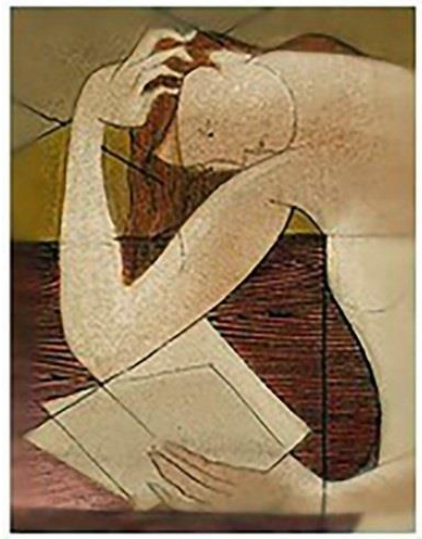

Nau Literária

crítica e teoria da literatura em língua portuguesa

PPG-LET UFRGS

ISSN 1981-4526

https://seer.ufrgs.br/NauLiteraria

V. 17, n.1 - 2021

Dossiê Clarice Lispector: Iluminações para o tempo presente

\section{Considerações Finais}

Neste artigo, buscamos apresentar a tessitura das teias comunicacionais, mnemônicas e editoriais em torno da celebração do centenário de nascimento de Clarice Lispector no ano de 2020. Nota-se que a ambiência digital permite que a rememoração seja transversal acionando acervos bibliográficos da escritora em recortes distintos que sugerem enquadramentos outros do fazer-memória. Este, por sua vez, se faz pela reapresentação das narrativas compreendidas nesses acervos. Para sustentar nossa análise, apresentamos quatro lançamentos motivados pela chegada da data redonda dos cem anos da escritora: site.claricelispector.ims.com.br, Podcast da Clarice, \#365diasdeClarice nas redes sociais Facebook e Instagram e a reimpressão em capas que reproduzem parte do acervo de pinturas de Clarice Lispector.

Ainda assim, a temática não se esgota neste trabalho, mas nos indica, como horizonte, a relevância dessas iniciativas para a preservação da memória sociocultural, literária e editorial de Clarice Lispector em ritos de calendário que podem promover a renovação periódica daquilo que se torna memorável como a celebração de um centenário.

\section{Referências}

COLOMBO, Fausto. Os arquivos imperfeitos. São Paulo: Perspectiva, 1991.

DOUGLAS, Mary e ISHERWOOD, Baron. $O$ mundo dos bens: para uma antropologia do consumo. Rio de Janeiro: UFRJ, 2006.

GONDAR, Jô. Quatro proposições sobre memória social. In: GONDAR, Jô; DODEBEI, Vera (Org). O que é memória social? Rio de Janeiro: Contracapa, 2005. 

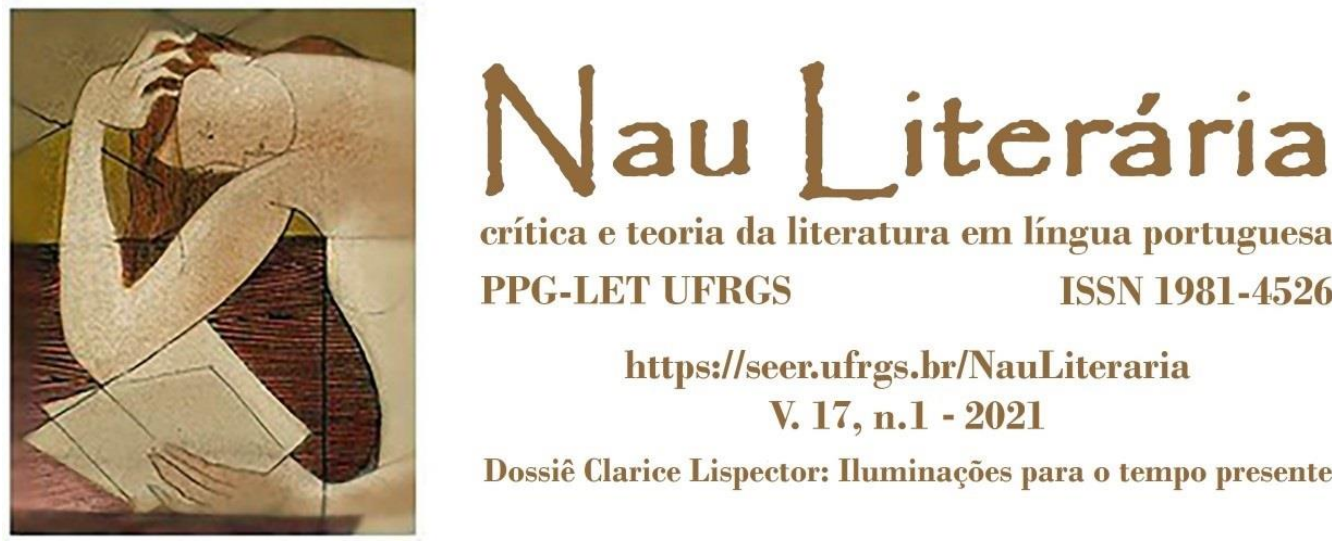

crítica e teoria da literatura em língua portuguesa PPG-LET UFRGS ISSN 1981-4526

https://seer.ufrgs.br/NauLiteraria V. 17, n.1 - 2021

Dossiê Clarice Lispector: Iluminações para o tempo presente

NUNES, Mônica R. F. O mito no rádio: a voz e os signos de renovação periódica. São Paulo: Annablume, 1993.

POLLAK, Michael. Memória, esquecimento, silêncio. Estudos Históricos. Rio de Janeiro, Vol. 2. n. 3, 1989, p 3-15. Disponível em

http://bibliotecadigital.fgv.br/ojs/index.php/reh/article/viewFile/2278/1417

PROSS, Harry. A comunicação e os ritos de calendário. Entrevista cedida à Projekt - Revista de Cultura Brasileira e Alemã. São Paulo, n. 7, p. 7-10, jun. 1992.

RICOEUR, Paul. A memória, a história, o esquecimento. Campinas: Editora Unicamp, 2007.

SILVERSTONE, Roger. Por que estudar a mídia? São Paulo: Edições Loyola, 2002. 